\title{
Analysis on Development of Folk Culture Industry
}

\author{
Bianling Zhang \\ Huanghe Science and Technology College \\ Zhengzhou, China
}

\begin{abstract}
Henan has a long history and rich folk culture resources and diversified folk culture forms. At present, Henan does not make enough efforts to produce and develop folk culture resources. The development of folk culture industry is at initial stage. Problems such as not obvious brand advantage of folklore products, small industry scale and relatively low transformation rate of resources and lack of innovation and talents are prominent. In order to realize sound development of Henan folk culture industry, it is suggested to integrate available resources to build and develop Henan folk culture industry, use advanced cultural development strategy, implement brand driving strategy and create creative industry of folk culture, construct market of folk culture industry as well as excavate innovative approach to promote development of folk culture.
\end{abstract}

Keywords-Henan folk culture; industry; development; analysis

\section{INTRODUCTION}

Folk custom refers to life culture created, enjoyed and inherited by people of a country or a nation. [1] It is physical and spiritual cultural phenomenon formed by ordinary people in daily production and life. It is universal, changeable and inheritable. It is the culture with different types and patterns created, passed, accumulated and changed by people under different ecologies, different cultural environment as well as different psychological background. Folk culture is the basis and important part of national culture and unique cultural phenomenon of a nation.

For a long time, researches on folk culture are often confined to the category of academic research, generally not involving development and sales of cultural products; development, production and sales of folk culture products are carried out in business circle. They seldom communicate with specialists and scholars that engage in researches on folk custom. Culture separates from industry. It leads to many problems, such as make folklore products lack academic grade, academic feeling and cultural concept. Nowadays, information industry develops rapidly and market competition is fierce. We should consider how to develop the market of folk culture industry, strengthen "hematopoietic" function of folk culture cause, and combine cultural study with product development, make good for deficiency, and form scale effect as well as serve local economy and culture. It is a new task in front of folk culture workers, a sacred mission endowed by the era, one of the ways of productive protection and important channel to inherit folk culture.

\section{CHANGE IDEA AND IMPROVE IDEOLOGICAL UNDERSTANDING OF INDUSTRIALIZATION OF FOLK CULTURE}

With continuous deepening of the reform and opening up, market competition becomes increasingly fierce, not only impact enterprise and market but also strongly impact culture and thought. In order to realize industrialization development of folk culture, it is necessary to change ideology.

- Folk culture workers shall get a clear understanding of the situation and have the sense of urgency and responsibility. At present, dramatic development of market economy boosts from China's South-East coastal areas to central and western regions. It is hardwon opportunity for development of provinces and cities in central and western regions, especially for provinces such as Henan in center of the Central Plains. Folk culture of the Central Plains concerns future destiny of cultural development as well as overall situation of construction of Central Plains Economic Region. Prospering folk culture industry in the Central Plains and local economy also concerns general situation of folk culture development in our country, because the development and industrialization of folk culture is important part of economic and cultural system in each area.

- Folk culture workers shall overcome fear of difficulty and realize necessity of folk culture industrialization. Realization of folk culture industrialization still has a long way to go. We cannot succeed with fear of difficulty. The separation between cultural research and product development is caused by planned economy and cannot adapt to the change of situation of market economy. Realizing cultural industrialization and developing market of cultural products can make cultural research workers become rich and prosper local economy. In order to get out of the trouble, cultural workers must free their mind and firmly develop folk culture products, which is the only road to realize folk culture industrialization.

- Folk culture workers shall enhance confidence, clearly see possibility of folk culture industrialization and know tasks faced by folk culture development. Because rapid development of information technology promotes progress of knowledge economy, "human are stepping in economy era that takes occupation and configuration of intellectual resources and production, distribution, utilization and consumption of knowledge as the most 
important factors". [2] In the 21st century, high and new technology develops rapidly and knowledge economy becomes global wave. The so-called knowledge economy refers to economic industry with sustainable development that takes high technology industry as the first pillar industry and depends on intellectual resources. In other words, knowledge and information should become basic elements of modern production. Knowledge is the driving force of modern economic development, namely "science and technology are the primary productive forces" said by comrade Deng Xiaoping. Conform to development trend of information technology industrialization, use new technology to arrange, excavate and develop folk culture resources, make economy that depends on folk culture move towards industrialization, form scale and receive effect. Since the reform and opening up, the protection, arrangement and development of folk culture in the Central Plains make remarkable progress. High quality folk culture in Central Plains emerges continuously. Overall strength, competitiveness and development as well as utilization efficiency are promoted obviously, creating new situation of innovation, development and inheritance of folk culture in Central Plains.

\section{BASIC THINKING TO ESTABLISH INDUSTRIALIZATION OF FOLK CULTURE}

In recent years, with improvement of living standard, people have increasing requirements for diversified and multilayered spiritual and cultural products. Developing folklore products is to seek social benefits as well as meet multilayered spiritual pursuit of people. Development of diversified folk culture makes it form unique cultural industry. It is by no means easy and requires cooperation of many aspects to strive to achieve three combinations, carry forward Central Plain Culture as well as prosper cultural industry.

\section{A. Combine Product Development and Research on Folk Custom}

The Central Plains have abundant folk culture resources, strong foundation for Henan to promote development of cultural industrialization and create famous brand of cultural industry. Experts of folk custom shall be well-trained and proficient in professional work, so that they can break through key technology of cultural industry and develop burgeoning cultural industry. They are best qualified to speak on what kind of folk culture has characteristics and what kind of folk culture can be developed, so the team that researches on folk culture is talent team of folk culture development. It is necessary to guide them to turn main energy to new product development, strive to combine cultural research with product development, turn research results into productivity and use their innovative wisdom to produce economic benefits. However, they may be unfamiliar with product marketing and do not know how to do business, so it requires entrepreneurs to play positive role, because entrepreneurs clearly know which products are popular among customers and what kind of products has good market outlet but do not know how to select folklore products.
If talent team of folk custom and entrepreneurs cooperate with each other and make good for deficiency, discuss development of folklore products, it will make the development of folklore products and folk custom industrialization take new steps, hasten the production of new type folk culture formats in Central Plains and revitalize folk culture development in Central Plains.

\section{B. Combine Folk Culture with Tourist Industry}

Tourist industry is an emerging industry that has economic, environmental, social and cultural functions. Under the background of current adjustment of industrial structure, tourist industry becomes new economic growth point. The development of tourist industry will inevitably drive the development of business, enterprise as well as hotel and restaurant industry, and then promote local economic development, enlarge market demand and increase employment opportunities. Tourist activity belongs to cultural consumption, because most tourist activities have rich cultural connotation. The combination of folk culture and tourist industry can effectively publicize folk culture with the help of tourism landscape and scenic spots as well as continuously enrich contents of tourist industry and inject new vitality to tourist industry. Tourism resources mainly aim at meeting psychological demands of travelers in cultural significance. If tourist industry becomes increasingly flourishing, folk culture will develop better and better. They complement each other.

\section{Create Multi-layered Tourism Products to Attract Consumers}

Folk culture products are various and have large stock, including static products and dynamic products. Static products refer to specific materialized products, such as jun porcelain products, Nigugu, New Year wood-block painting and Huaiyang clay dogs; dynamic products refer to folk custom performance, such as Shaolin Kung Fu, Pangtzu of Henan, big bronze performance of Jiaxian and magic performance of Baofeng. Both static and dynamic products show local full-bodied folklore characteristics. How to combine static products with dynamic products of folk culture? For example, combine folk exhibition with aerobatic demonstration of folk custom (such as paper-cut, sculpture or calligraphy), combine product sale with folk custom performance. In this way, the development of folklore products will be very impressive, lively and vivid and meet different requirements of tourists at different cultural levels. Depend on tourism landscape and scenic spots and launch folklore products and performance on the market, so that it will be richer and more colorful, promote fine reputation of tourism resources, get more ideal social and economic benefits.

\section{CARry OUT CORRECT PRODUCT POSITIONING,} STANDARDIZE OPERATION SPECIFICATION OF FOLK CULTURE INDUSTRIALIZATION

In order to form industry sale of folklore products development, it is necessary to follow law of the market, grasp market information and designedly develop products according to market demand. 
Correct product positioning is the prerequisite to develop folklore products. There are a wide range of folklore products in each area and nation. The selection of preferred products and product positioning must go through product screening and call up entrepreneurs and experts to discuss and decide.

The proposition and establishment of development mechanism of folk culture products help theoretical development of folk culture products and have practical guiding significance in guiding design and development of folk culture products in practice and promoting sales and marketing campaign of folk culture products. Product positioning must pay attention to: Firstly, highlight local features and develop featured products. Countless facts prove that: things will have more development value if it has more characteristics; things with national characteristics have more market outlet. Quite a few featured products have indomitable vitality and great development potential, but it still remains to be excavated and developed. Secondly, take products that need small investment but have quick results as preferred products. The ultimate purpose to develop folklore products is to get economic benefits and promote economic development. If products have long development cycle, slow turnover of capital and too many intermediate link, large input of manpower and financial resources, the benefits produced will not be considerable, which is easy to dampen the enthusiasm of the masses. Take products with "short cycle, small investment and quick results and high efficiency" as preferred products, so we can achieve good economic benefits in a very short period of time. Thirdly, use local materials to process. Products with full-bodied local features can realize preferential development. In development of folklore products, it is the best way to use local materials to process locally, reduce intermediate links, so that we can reduce cost, boost profits and increase economic income.

\section{CONCLUSION}

Nowadays, countries in the world actively carry out rush registration of folk culture. Contradictions and disputes caused by cultural conflicts become important factors that influence peace and development of the world. It has profound value and meaning to explore inheritance and innovation of folk culture. Folk culture becomes carrier of national identity, link of national solidarity. Its harmonious values increasingly become core value of human in globalization era. Henan has abundant folk culture resources and broad development prospect. In the process of inheritance and innovative development, Henan folk culture needs the help of new cultural formats to form development scale and industrial effect. Launch folk culture resources on the market, fully discover and use folk culture resources, realize transformation from resources to products and make it become cultural products with higher value to create more economic value.

\section{REFERENCES}

[1] Zhong Jingwen. Introduction to Folklore [M], Shanghai: Shanghai Literature and Art Publishing House, 1998.
[2] Zhang Bangshu. Exploration on Concept of Information Literacy [J], Science and Technology Information (scientific teaching and research), the 17 th issue of 2007. 